Arqueologia Pública

ENTREVISTA

\title{
A ARQUEOLOGIA DA \\ REPRESSÃO E DA RESISTÊNCIA: \\ UMA CONVERSA COM ANDRÉS ZARANKIN
}

ENTREVISTADORES

Victor Henrique da Silva Menezes

Júlia Negov de Oliveira 


\section{ENTREVISTA}

\section{A ARQUEOLOGIA DA REPRESSÃO E DA RESISTÊNCIA:}

\section{UMA CONVERSA COM ANDRÉS ZARANKIN}

\section{ENTREVISTADO}

Andrés Zarankin - Professor titular da Universidade Federal de Minas Gerais (UFMG) e pesquisador associado do Laboratório de Arqueologia Pública Paulo Duarte (LAP/ NEPAM/Unicamp). Email: zarankin@yahoo.com

\section{ENTREVISTADORES}

Victor Henrique da Silva Menezes - Graduando em História pela Unicamp e estagiário do Laboratório de Arqueologia Pública Paulo Duarte (LAP/NEPAM/Unicamp). Contanto: henrique.menezes92@gmail.com

Júlia Negov de Oliveira - Graduanda em História pela Unicamp e colaboradora no Laboratório de Arqueologia Pública Paulo Duarte (LAP/NEPAM/Unicamp). Contanto: ju.noliveira@yahoo.com.br

\section{RESUMO}

Na presente entrevista, o leitor encontrará uma breve definição do conceito "Arqueologia da Repressão e Resistência", bem como um panorama sobre as possibilidades desse campo de pesquisa. Além de ressaltar a importância de estudos nessa área, o professor Andrés Zarankin tece comentários acerca do processo de musealização, e ressalta a importância do contato com as comunidades e os agentes históricos.

Palavras chave: Arqueologia da Repressão e Resistência; estudos do tempo presente; musealização; arqueologia pública. 


\section{INTRODUÇÃO}

Andrés Zarankin é professor titular do Departamento Antropologia e Arqueologia da FAFICH-UFMG e doutor pela Universidade Estadual de Campinas, com enfoque na área de Arqueologia e análise arquitetônica. Montou e liderou a equipe de escavação do Centro de Detenção Clandestino Clube Atlético em Buenos Aires, entre os anos de 2002 e 2003. Possui experiência e pesquisas nas áreas de Arqueologia Histórica, Arqueologia Antártica, Arqueologia do Capitalismo, Arqueologia da Arquitetura e dos campos de concentração latino americanos.

$\mathrm{Na}$ entrevista que se segue, Zarankin conta sobre sua trajetória como estudioso da cultura material e sua relação com os movimentos pelos direitos humanos. Posiciona-se sobre a importância das pesquisas na área de Arqueologia da Repressão e Resistência, sobre o papel do arqueólogo e suas ações na comunidade relacionadas com Arqueologia Pública, e indica as possibilidades para jovens pesquisadores interessados nessa temática.

Entrevistadores: Para começar, agradecemos ao professor por ter aceitado o convite para participar desta entrevista, e, gostaríamos que falasse um pouco acerca de sua trajetória como estudioso da cultura material, e em particular, do tema da repressão e resistência. Quais foram os caminhos que te levaram a realizar pesquisas na área de Arqueologia?

Andrés Zarankin - Essa é uma pergunta difícil de responder, já que as escolhas aconteceram em diferentes épocas e por diferentes motivos. Talvez possa colocar como eixo conector meus pais. Quando tinha seis anos, eles me deram de presente um livro intitulado A grande aventura da Arqueologia, o que me fez decidir a tão curta idade virar arqueólogo. Claro que minha ideia da profissão estava associada aos estereótipos dos tesouros e aventuras, que mais tarde seria reforçado por Indiana Jones (o que também intensificaria minha vontade de virar arqueólogo). Por outro lado, meus pais sempre participaram ativamente de movimentos políticos e de diretos humanos, o que fez que mantivesse sempre uma posição de engajamento, principalmente nas reivindicações por justiça relacionada aos crimes da ditadura Argentina. O problema foi que estes dois campos na minha vida permaneceram separados por muito tempo, já que na universidade era ensinado que a descoberta do passado real deveria ser pura e não contaminada. Além disso, trabalhava-se com um passado distante.

Foi a partir de meu amadurecimento como arqueólogo, da leitura extracurricular de autores como Hodder, McGuire, Shanks, Tilley, Beaudry, Funari, Tania Andrade Lima, 
dentre outros, que minha cabeça começou a mudar, e entendi que tinha vivido preso dentro de limites com medo que o que fizesse não fosse mais considerado arqueologia. Neste momento, compreendi que arqueologia e política estavam atravessadas uma pela outra. Assim, porque não utilizar a arqueologia para tratar no mundo moderno, de temas como dominação, resistência, violência, ideologia, capitalismo, entre outros? Surgiram assim meus primeiros trabalhos que buscavam analisar a ideologia na arquitetura. Posteriormente meu interesse se voltou para o tema da ditadura e violência política. Já existia o exemplo do EAAF (Equipe Argentina de Antropologia Forense), porém, este inspirador grupo de vanguarda sempre tinha funcionado fora do universo acadêmico (e de fato não era costume deles publicar ou participar de congressos e eventos científicos). Neste momento, 2002, o governo da cidade de Buenos Aires abriu concurso para o desenvolvimento de um trabalho de escavação no centro clandestino Club Atlético. Era uma grande oportunidade, então montei uma equipe e apresentei um projeto. Esse tinha como objetivos principais o estudo da arquitetura do lugar como estratégia repressiva e, ao mesmo tempo, era a construção de uma memória material sobre a repressão. Nosso projeto foi escolhido e durante um ano trabalhei de graça, unicamente pelo meu convencimento de que finalmente estava podendo reunir duas grandes questões que sempre me instigaram, a arqueologia e a luta por justiça.

Entrevistadores: Existe consenso hoje, no meio acadêmico, na definição do campo da arqueologia da repressão e da resistência? Como você o define?

Andrés Zarankin - O conceito foi proposto por Pedro Paulo Funari e por mim num livro que leva este título em 2006. Posteriormente, foi utilizado por outros pesquisadores de formas diversas. Nossa ideia original foi simplesmente desenvolver uma Arqueologia política que tivesse como foco o estudo dos processos de violência política na América Latina, entre as décadas de 1960 e 1980. É importante salientar que sempre utilizamos os conceitos de repressão (para falar das políticas do sistema), mas também de resistência, para mostrar que as pessoas não são passivas e aceitam de forma submissa as imposições. Mas, pelo contrário, estas desenvolvem táticas (segundo a definição de De Certau) a partir das quais lutam, se enfrentam e às vezes conseguem resistir ou mudar aquilo que lhes é imposto.

Entrevistadores: No contexto da América do Sul, qual é a função e a importância de realizar pesquisas no âmbito da Arqueologia da Repressão e Resistência?

Andrés Zarankin - Pessoalmente, acredito que essas pesquisas são da maior importân- 
cia. Não só para desenvolver uma visão critica do passado recente, e, portanto, de uma memória do que não queremos que aconteça novamente, mas também para compreender as estratégias de reprodução do sistema, para não continuarmos a acreditar que as desigualdades sociais são naturais e que as pessoas comuns não tem força suficiente para construir outra realidade. A história não só da América do Sul, mas também da América Latina tem sido de lutas e conflitos e a arqueologia coloca-se como uma ferramenta política a serviço dos povos (dentre as quais destaco os estudos do presente), tendo o potencial de ajudar a reforçar sociedades mais democráticas.

\section{Entrevistadores: Como esse campo da Arqueologia estuda o uso dos espaços pelos governos totalitários e autoritários?}

Andrés Zarankin - A arqueologia como disciplina nos capacita para efetuar leituras sociais a partir da materialidade. O espaço é um dos componentes centrais para o estudo da cultura material, já que este é transformado em lugar a partir de uma distribuição de pessoas e objetos criando funcionalidades e sentidos. O controle do espaço, como assinala Foucault, tem sido uma estratégia recorrente por parte do sistema a partir do século XVII e principalmente do XVIII. Ter o poder de distribuir pessoas e coisas é uma estratégia eficaz de disciplina. No caso especifico dos governos totalitários, separar e reunir os inimigos facilita o exercício do poder, de controlar e aniquilar. A arqueologia pode utilizar estes lugares para discutir a estratégias repressivas (assim como também as resistências como uma linha alternativa de estudo).

Entrevistadores: Você poderia nos apresentar um exemplo concreto de estudo desenvolvido no campo da Arqueologia da Repressão e Resistência?

Andrés Zarankin - Existem múltiplos exemplos que vão desde a recuperação dos corpos dos desaparecidos, como parte dos estudos em antropologia forense, que buscam determinar quando e como morreu a pessoa, até outros estudos que trabalham a organização espacial dos campos de concentração, passando por análises da roupa encontrada junto com os corpos dos desaparecidos, os grafites em paredes de prisões, a construção de lugares para a memória sobre as ditaduras, assim como muitos outros. Vários destes trabalhos podem ser encontrados nos livros Arqueologia da Repressão e da Resistência na América Latina na era das ditaduras (Funari \& Zarankin, 2008) e Histórias Desaparecidas (Zarankin, Salerno e Perosinio, 2012).

Entrevistadores: Como as pesquisas arqueológicas interagem com as vítimas dos 
regimes totalitários na América do Sul? E quanto aos familiares das vítimas, como eles podem dialogar com tais estudos?

Andrés Zarankin - Fora as equipes de Antropologia Forense, que em geral atuam como ONGs, só recentemente a Arqueologia tem entrado de forma sistemática na temática da repressão e resistência durante as ditaduras da segunda metade do século XX. Ademais, os arqueólogos estão acostumados a trabalhar de forma isolada da comunidade e dos atores sociais que produziram o registro arqueológico (que em geral estão mortos há muitas centenas de anos). Isto tem dificultado a interação entre os arqueólogos e os sobreviventes ou seus familiares. Porém, com sorte isto está mudando e, atualmente, em grande parte dos projetos, vítimas, familiares, organismos de direitos humanos, dentre outros, participam ativamente das pesquisas e são incluídos na tomada de decisões sobre o rumo dos projetos.

Entrevistadores: É possível desenvolver pesquisas no campo da Arqueologia da Repressão e Resistência numa perspectiva da Arqueologia Pública?

Andrés Zarankin - Acredito que não exista outra forma de desenvolver uma Arqueologia da Repressão que não seja pública e que não implique um contato e uma colaboração com as vítimas, com suas famílias ou com a sociedade. Qualquer outro intento seria retornar às práticas de uma arqueologia tradicional e autoritária, dentro da qual o arqueólogo é o dono da verdade sobre o passado, indo contra os próprios princípios implícitos numa arqueologia da repressão e a resistência.

Entrevistadores: Como os museus podem tratar da Arqueologia da Repressão e Resistência? Como eles podem atuar/trabalhar com a cultura material advinda de tais estudos?

Andrés Zarankin - Este é um tema que deveria ser discutido com os museólogos em conjunto com os sobreviventes, agrupações de direitos humanos, etc. Existem muitas possibilidades de apresentar tanto as informações como a cultura material recuperada. Cada uma destas vai ter um efeito diferente sobre o público, que pode ir desde uma sensação de esperança (monumentos, objetos feitos pelos prisioneiros, espaços repressivos agora limpos e cheios de espaços verdes) até o maior sofrimento que seja possível imaginar (ex. manchas de sangue, instrumentos de tortura, roupa furada por balas, etc.). Como mencionei, não é o arqueólogo ou o museólogo quem deve escolher como deve ser apresentada a história do lugar ou os objetos recuperados, mas esta decisão precisa

256 | Revista de Arqueologia Pública, No. 10, pp. 252-257, Dezembro de 2014 
ser pensada com os protagonistas dessa história e com a sociedade.

Entrevistadores: O que há ainda para ser feito nesse campo da Arqueologia nas pesquisas que tem como foco a América do Sul?

Andrés Zarankin - Tudo! De fato, estamos frente a um tema que apenas recentemente a Arqueologia tem começado a tratar dentro do âmbito acadêmico. São mínimas as pesquisas existentes, pelo que considero este tipo de estudos um dos grandes desafios da arqueologia na atualidade.

Entrevistadores: Agora, para finalizar: aos nossos leitores brasileiros que tiverem interesse em desenvolver pesquisas na área de Arqueologia, em especial, voltadas aos estudos da Arqueologia da Repressão e da Resistência, quais são os possíveis caminhos a percorrer?

Andrés Zarankin - Não existe diferença com os percursos de qualquer pesquisa, isto é, dentro da problemática da Arqueologia da Repressão e Resistência, escolher um objeto de estudo e pensar quais as perguntas que querem ser respondidas. Também é fundamental pensar uma metodologia adequada. Tudo isto pode ser feito em diferentes níveis de pesquisa que vão desde um TCC até um mestrado ou tese de doutorado. Atualmente, acredito que grande parte dos cursos de Arqueologia no país está aberta para receber estudantes interessados na temática.

257 Revista de Arqueologia Pública, No. 10, pp. 252-257, Dezembro de 2014 